\title{
The Arabic Version of the Tegner Activity Scale in Patients with Anterior Cruciate Ligament Reconstruction: Translation, Validation, and Cross-Cultural Adaptation
}

\author{
Msaad Alzhrani ${ }^{1}$, Hosam Alzahrani ${ }^{2}$ D and Yasir S. Alshehri ${ }^{3, *}$ \\ 1 Department of Physical Therapy and Health Rehabilitation, College of Applied Medical Sciences, \\ Majmaah University, Al Majmaah 11952, Saudi Arabia; m.alzhrani@mu.edu.sa \\ 2 Department of Physical Therapy, College of Applied Medical Sciences, Taif University, \\ Taif 21944, Saudi Arabia; halzahrani@tu.edu.sa \\ 3 Department of Physical Therapy, College of Medical Rehabilitation Sciences, Taibah University, \\ Madinah 42353, Saudi Arabia \\ * Correspondence: yshehri@taibahu.edu.sa
}

check for updates

Citation: Alzhrani, M.; Alzahrani, H.; Alshehri, Y.S. The Arabic Version of the Tegner Activity Scale in Patients with Anterior Cruciate Ligament Reconstruction: Translation,

Validation, and Cross-Cultural Adaptation. Int. J. Environ. Res. Public Health 2022, 19, 1987. https:// doi.org/10.3390/ijerph19041987

Academic Editor: Paul B. Tchounwou

Received: 14 January 2022

Accepted: 8 February 2022

Published: 10 February 2022

Publisher's Note: MDPI stays neutral with regard to jurisdictional claims in published maps and institutional affiliations.

Copyright: () 2022 by the authors Licensee MDPI, Basel, Switzerland. This article is an open access article distributed under the terms and conditions of the Creative Commons Attribution (CC BY) license (https:// creativecommons.org/licenses/by/ $4.0 /)$.

\begin{abstract}
Background: The Tegner activity scale is a patient-reported questionnaire that is frequently used to measure activity levels in patients with anterior cruciate ligament reconstruction (ACLR). The purpose of this study was to translate, cross-culturally adapt, and validate the Tegner activity scale into Arabic. Methods: The Tegner activity scale-Arabic version (TAS-Ar) was forward and backward translated, cross-culturally adapted, and validated according to established guidelines. Seventy-five patients who underwent ACLR were instructed to complete the TAS-Ar, the International Knee Documentation Committee (IKDC) subjective knee evaluation form, and the Knee Injury and Osteoarthritis Outcome Score (KOOS) scale. The test-retest reliability of the TAS-Ar was assessed in 39 patients. Statistical tests were conducted to test the reliability and construct validity of the TAS-Ar. Results: The TAS-Ar showed excellent test-retest reliability, with intraclass correlation coefficients of $0.836(p<0.001)$. The TAS-Ar was significantly correlated with the IKDC (Spearman's rho $=0.476$, $p<0.001$ ), all KOOS subscales (Spearman's rho $=0.195-0.497, p<0.05$ ), and the KOOS total score (Spearman's rho $=0.469, p<0.001$ ). Conclusions: The Arabic version of the Tegner activity scale is a reliable and valid measure that can be used to evaluate the activity level of Arabic-speaking patients following ACLR.
\end{abstract}

Keywords: ACL reconstruction; Tegner activity scale; activity level; knee; cross-cultural adaptation; patient-reported outcome

\section{Introduction}

Anterior cruciate ligament (ACL) rupture is a common sport-related knee injury that affects young individuals in Saudi Arabia [1]. ACL rupture can significantly decrease the stability of the knee joint and the ability to return to work/sport activities [2]. As a result, many patients choose to undergo ACL reconstruction (ACLR) with the goal of restoring normal knee function and subsequently returning to the pre-injury level of sport activities [3]. However, to determine the outcome after ACLR, it is important for surgeons and rehabilitation specialists to measure the level of work/sport activities of patients before ACL injury and after reconstruction [4]. Documenting such information can help health care providers to monitor the prognosis of patients' activity levels during rehabilitation post-ACLR and to determine whether these patients reach their pre-injury level of work/sport activities.

To assess work/sport activities, Tegner and Lysholm [5] developed a patient-reported questionnaire known as the Tegner activity scale (TAS). The TAS provides a list of 11 levels of grading work and sport activities for patients to choose from, ranging from 0 , which 
represents sick leave or disability pension because of knee problems, to 10, which corresponds to participation in national and international elite competitive sports [5]. The TAS is reliable, valid, and responsive for assessing activity levels in patients with ACL injuries [6]. In addition, this is a short single-page scale that can be easily applied [6].

TAS is one of the most frequently used scales in ACL-related studies to document the level of work/sport activities of patients with ACL injury and ACLR [4,7-9]. Moreover, the TAS has been translated and cross-culturally adapted into different languages [10-14]. To our knowledge, there is a lack of reliable and valid Arabic outcome measures that can be used to evaluate the level of work/sport activities in patients after ACLR. Therefore, the purpose of this study was to translate, cross-culturally adapt, and validate the TAS into Arabic (TAS-Ar) in Arabic-speaking patients after ACLR. We believe that the TAS-Ar will help health care providers and researchers in Arabic-speaking countries to document the level of work/sport activities of patients with ACLR, as well as to facilitate multinational and multicultural research collaborations.

\section{Materials and Methods}

\subsection{Translation and Cross-Cultural Adaptation}

Translation and cross-cultural adaptation of the TAS was performed according to the Guidelines for the Process of Cross-Cultural Adaptation of Self-Report Measures [15]. Permission to translate the scale was obtained from the original author. Two physical therapists, who were native Arabic speakers with good knowledge of English, independently translated the scale into Arabic. The original version of the TAS and the two translations were reviewed and discussed with a third bilingual physical therapist to correct any conceptual discrepancies and to establish a single Arabic version of the TAS (TAS-Ar). The three physical therapists are faculty members and researchers working on orthopedic research projects. A consensus meeting was held by the translators and the reviewer to confirm the initial version of the TAS-Ar. Then, the TAS-Ar was back-translated into English by two native English speakers with good knowledge of Arabic. There were no major differences between the original English version and the back translation. Subsequently, the translators held a meeting to finalize the final version of the TAS-Ar. In the final stage, a pilot study was conducted on five patients who had undergone ACLR at least three months prior. These patients were instructed to complete the TAS-Ar and to comment on the content of the questions, as well as on how to revise them if necessary.

\subsection{Participants}

Patients with ACLR were invited to participate in the study. The inclusion criteria were as follows: (1) age 16 years or older, (2) underwent primary unilateral ACLR with or without associated meniscal injury, (3) a minimum of three months post-surgery at the time of participation in the study, and (4) ability to read and write in Arabic. Patients were excluded if they had a history of knee injuries prior to the current ACL injury, bilateral ACL injuries, multi-ligament reconstruction, and/or articular cartilage repair. This study was approved by the Research Ethics Committee at Majmaah University. The procedures of this study were explained to the participants, and informed consent was obtained from all patients before participation. Then, an online-based questionnaire (SurveyMonkey, San Mateo, CA, USA) was sent to the patients to complete. For test-retest reliability, patients were asked to complete the same questionnaire twice within a month after the first attempt.

\subsection{Self-Reported Questionnaires}

The TAS is a one-item questionnaire that can be used to evaluate pre-injury and current activity levels [5]. The TAS consists of 11 levels of grading activities (e.g., daily living, recreation, and competitive sports), with a score of zero representing "Sick leave or disability pension because of knee problems", 1 to 5 representing activities ranging from sedentary jobs to heavy manual labor, 6 to 9 representing recreational and competitive 
sports, and a score of 10 can be achieved by participating in national and international elite sports (such as soccer) [5].

The construct validity of the TAS-Ar was tested against the Arabic versions of the International Knee Documentation Committee (IKDC) subjective knee evaluation form and the Knee Injury and Osteoarthritis Outcome Score (KOOS) [16,17]. The Arabic versions of the IKDC and KOOS scales have been found to be reliable and valid [16,17]. The IKDC is an 18-item self-reported questionnaire that is used to assess symptoms, sports activities, and function in patients with knee injuries. Responses are varied for each item. For example, item 6 dichotomizes answers into "yes" or "no"; items 1, 4, 5, 7, 8, and 9 use five-point Likert scales; and items 2, 3, and 10 use an 11-point numerical rating scale [6]. For each item, the response is scored using an ordinal method, with a score of 0 given to responses that represent the lowest level of function or highest level of symptoms. Scores for each item (excluding item 10a) are then summed to a given total score. The total score is transformed to a scale that ranges from 0 to 100 by dividing the sum of items by the maximum possible score and multiplying by 100 [6]. A higher IKDC score represents better knee function and fewer symptoms.

The KOOS scale consists of 42 items that are used to evaluate knee function in five subscales: pain, symptoms, activities of daily living, sport, and recreation function, and knee-related quality of life (QoL) [6]. The response for each item is rated on a five-point Likert scale (0-4), with a score of 0 given to responses that indicate no problems and 4 to responses that represent extreme problems. The five subscales are scored separately. For each subscale, scores are transformed to a $0-100$ scale by using this formula: $(100-$ (mean of the observed items within the subscale) $/ 4 \times 100)$. The total score for the KOOS scale is calculated as the mean of the five subscales. A higher score on the KOOS subscales and KOOS total is indicative of fewer knee-related problems.

\subsection{Statistical Analysis}

Descriptive analyses were presented as means, standard deviations (SDs), and percentages. The floor and ceiling effects of the TAS-Ar were evaluated to determine the percentage of patients with the lowest possible score (Tegner $=0$ ) and the highest possible score $($ Tegner $=10)$ on the TAS-Ar. These effects are considered to be present if more than $15 \%$ of patients choose the lowest or highest score on the scale [18]. Testretest reliability of the TAS-Ar was assessed using two-way random intraclass correlation coefficients (ICC) for absolute agreement with corresponding $95 \%$ confidence intervals (CIs). Reliability was considered "excellent" (ICC $\geq 0.75)$, "good" $(0.40 \leq$ ICC $<0.75)$, or "poor" (ICC $<0.40$ ). The absolute measurement error of the scale was expressed using the standard error of the measurement $\left(\mathrm{SEM}=\mathrm{SD}\right.$ pooled $\left.\mathrm{d}_{\text {standard deviation }} \times \sqrt{ }\left(1-\mathrm{ICC}_{2,1}\right)\right)$. The smallest detectable change for the individual score $\left(\mathrm{SDC}_{\text {individual }}\right)$ was calculated $\left(\mathrm{SDC}_{\text {individual }}=1.96 \times \sqrt{ } 2 \times \mathrm{SEM}\right)$. The smallest detectable change for the group score $\left(\mathrm{SDC}_{\text {group }}\right)$ was calculated $\left(\mathrm{SDC}_{\text {group }}=\mathrm{SDC}_{\text {ind }} / \sqrt{ } \mathrm{n}\right)[18]$.

Spearman's rank correlation was used to assess the construct validity between the TAS-Ar and the IKDC, KOOS subscales, and KOOS total scores. The correlation was considered "strong" (Spearman's rho $\geq 0.5)$, "medium" $(0.3 \leq$ Spearman's rho $<0.5)$, or "weak" (Spearman's rho < 0.3) [19]. All analyses were performed using SPSS software (version 26.0, IBM Corp., Armonk, NY, USA).

\section{Results}

\subsection{Cross-Cultural Adaptation}

The translation of the TAS from English to Arabic was performed without major issues. The subsequent back translation of the scale was also performed without any major linguistic or grammatical problems. The final translated version of the TAS-Ar was clear and easy to understand; moreover, no specific cultural adaptations were recommended during the translation process (Table 1). 
Table 1. The Arabic version of the Tegner Activity scale (TAS-Ar).

\begin{tabular}{|c|c|}
\hline - دوريات رابطة المحترفين مثل كرة قدم & $\begin{array}{l}\text { Level } 10 \\
\qquad \begin{array}{l}\text { المستوى } \\
\text { العاشر }\end{array}\end{array}$ \\
\hline 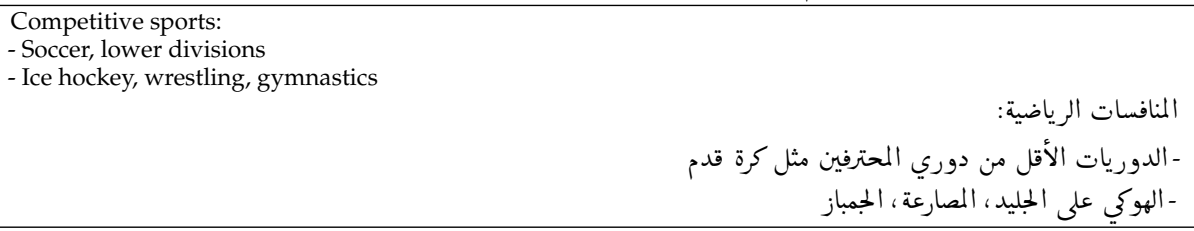 & $\begin{array}{l}\text { Level } 9 \\
\qquad \begin{array}{ll}\text { المستوى } \\
\text { التاسع }\end{array}\end{array}$ \\
\hline 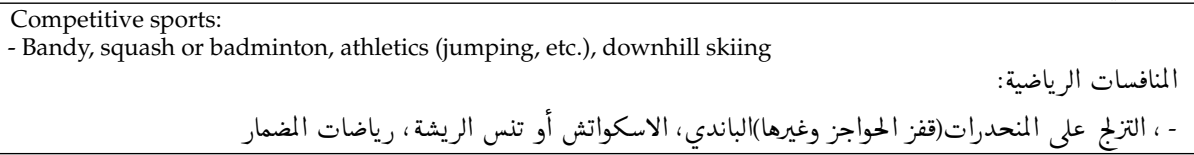 & $\begin{array}{l}\text { Level } 8 \\
\qquad \begin{array}{l}\text { المستوى } \\
\text { الثامن }\end{array}\end{array}$ \\
\hline 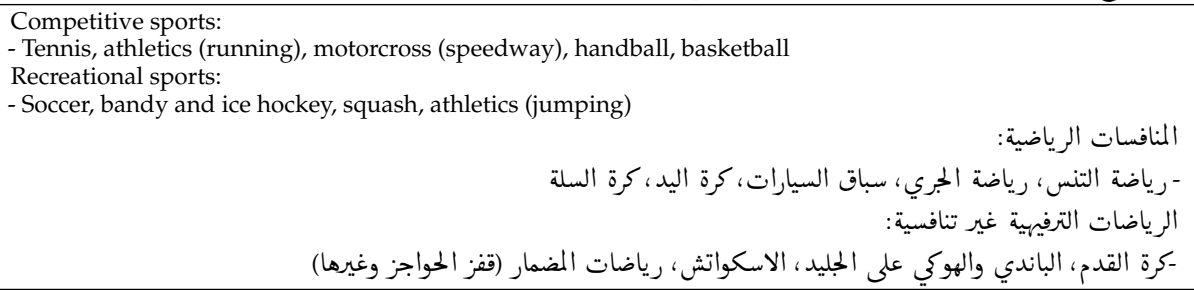 & 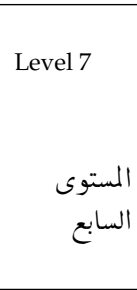 \\
\hline 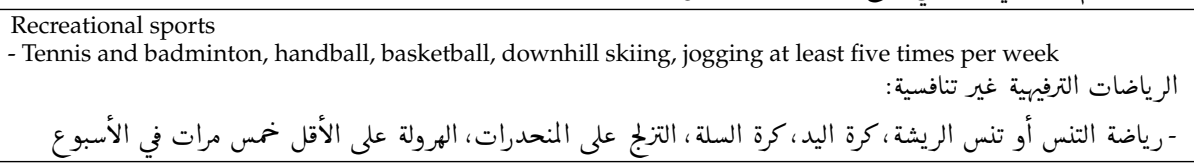 & $\begin{array}{l}\text { Level } 6 \\
\qquad \begin{array}{l}\text { المستوى } \\
\text { السادو }\end{array}\end{array}$ \\
\hline 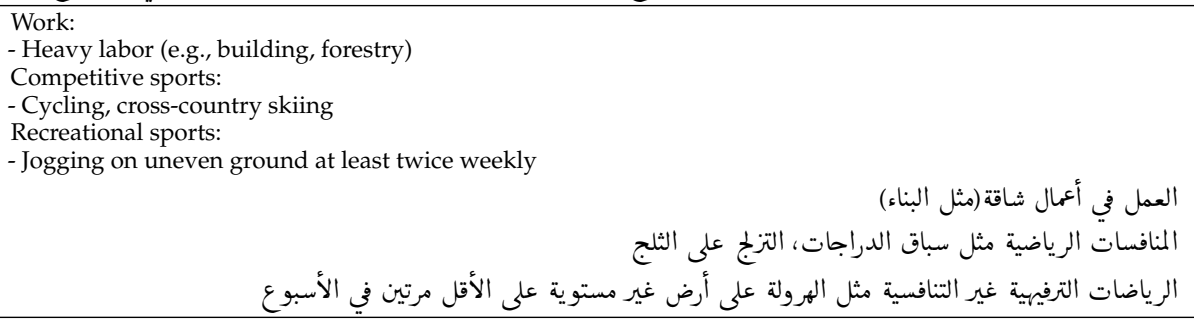 & المنامست \\
\hline 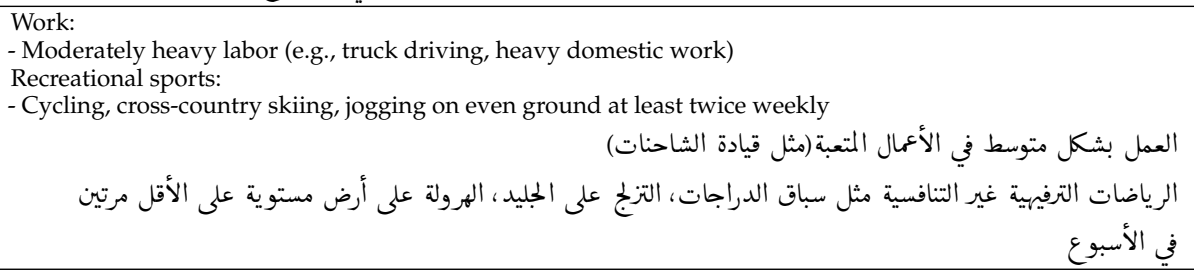 & المستوى \\
\hline $\begin{array}{l}\text { Work: } \\
\text { - Light labor (e.g., nursing) } \\
\text { Competitive and recreational sports: } \\
\text { - Swimming }\end{array}$ & $\begin{array}{l}\text { Level } 3 \\
\qquad \begin{array}{l}\text { المستوى } \\
\text { الثال }\end{array}\end{array}$ \\
\hline 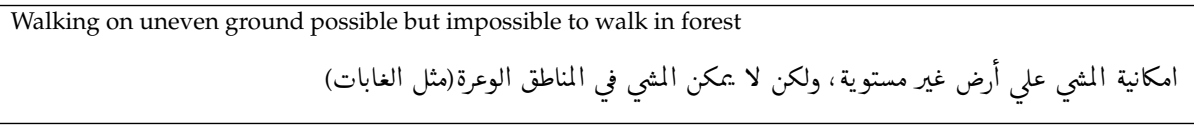 & $\begin{array}{r}\text { Level } 2 \text { المستوى } \\
\text { الثاني }\end{array}$ \\
\hline 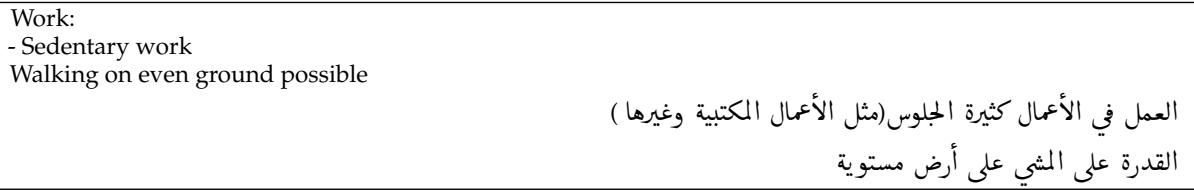 & $\begin{array}{l}\text { Level } 1 \\
\qquad \begin{array}{ll}\text { المستولى } \\
\text { المتول }\end{array}\end{array}$ \\
\hline في اجازة مرضية أو متقاعد بسبب مشاكل الركبة & $\begin{array}{l}\text { Level } 0 \\
\text { صفرتوى }\end{array}$ \\
\hline
\end{tabular}




\subsection{Study Participants}

A total of 110 patients with ACLR were invited to participate in this study. Of these patients, 25 did not respond, and four other patients had a previous knee injury other than the current injury. The remaining 81 patients met the inclusion criteria and completed the questionnaires. Six out of 81 patients failed to report the surgery date $(n=4)$ and the activity level on TAS-Ar $(n=2)$; therefore, their data were excluded from the analysis. The remaining data from 75 patients were included in the analysis (Figure 1). These patients were all men, with a mean age of $32.31 \pm 7.28$ years. The mean TAS-Ar was $4.60 \pm 2.75$. The demographic and clinical characteristics of the patients are shown in Table 2.

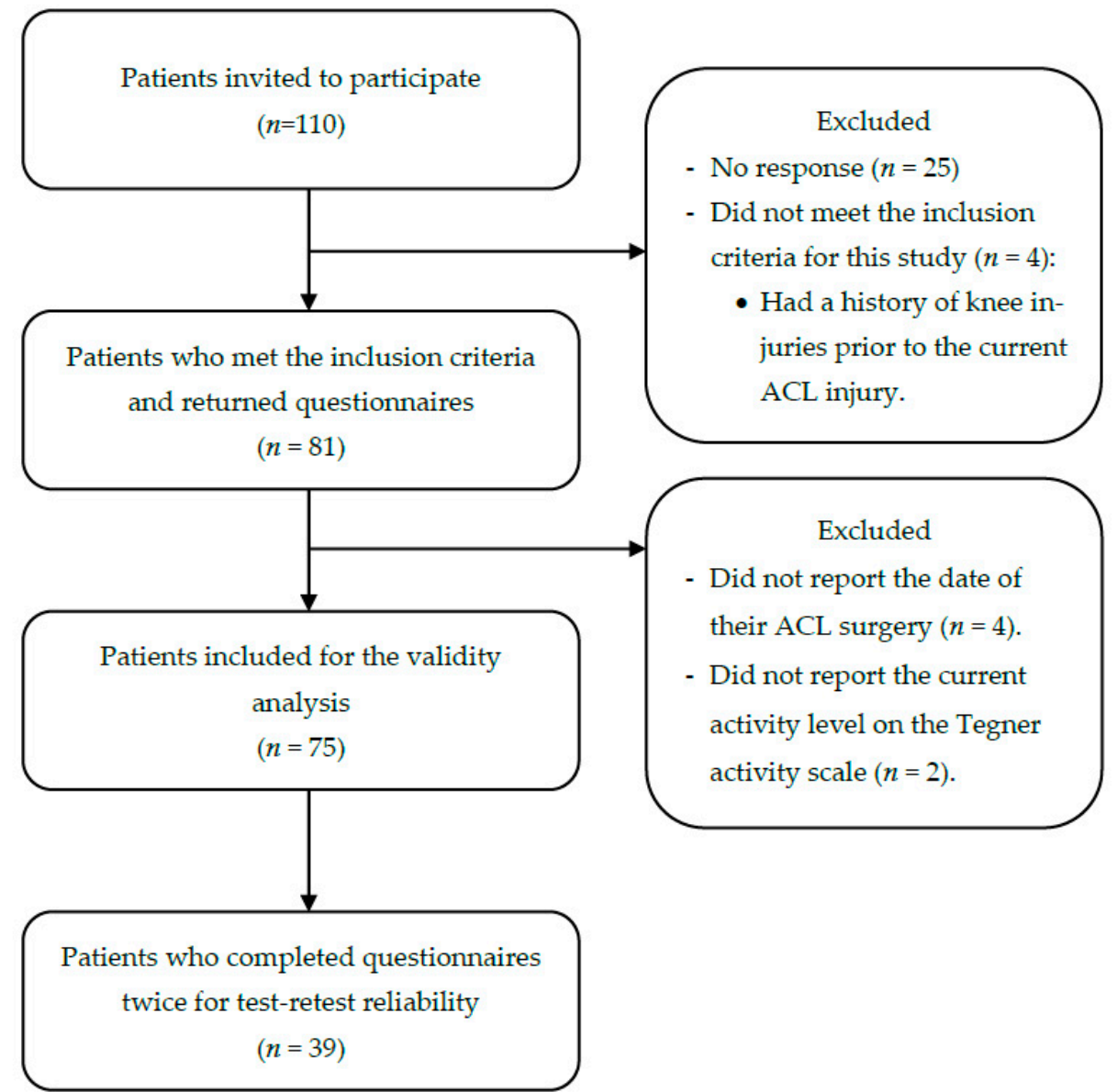

Figure 1. Flow diagram illustrating enrollment of patients with ACLR.

Table 2. Demographic and clinical characteristics of the participants *.

\begin{tabular}{ll}
\hline & $\begin{array}{l}\text { Patients with ACLR } \\
(\boldsymbol{n}=\mathbf{7 5})\end{array}$ \\
\hline Age, $\mathrm{y}$ & $32.31 \pm 7.28$ \\
\hline Sex, male, $\mathrm{n}$ & 75 \\
\hline Height, $\mathrm{cm}$ & $171.69 \pm 12.95$ \\
\hline Weight, $\mathrm{kg}$ & $85.33 \pm 22.19$ \\
\hline TAS-Ar, 0-10 & \\
Mean \pm SD & $4.60 \pm 2.75$ \\
Median (IQR) & $5(2 ; 7)$ \\
\hline IKDC, \% & $71.25 \pm 17.65$ \\
Mean \pm SD & $73.56(62.07 ; 82.76)$ \\
Median (IQR) &
\end{tabular}


Table 2. Cont.

\begin{tabular}{|c|c|}
\hline & $\begin{array}{l}\text { Patients with ACLR } \\
(n=75)\end{array}$ \\
\hline \multicolumn{2}{|l|}{ KOOS symptoms, \% } \\
\hline Mean \pm SD & $84.05 \pm 13.35$ \\
\hline Median (IQR) & $85.71(78.57 ; 92.85)$ \\
\hline \multicolumn{2}{|l|}{ KOOS pain, $\%$} \\
\hline Mean \pm SD & $88.04 \pm 12.58$ \\
\hline Median (IQR) & $91.67(83.33 ; 97.22)$ \\
\hline \multicolumn{2}{|l|}{ KOOS ADL, \% } \\
\hline Mean \pm SD & $91.09 \pm 11.74$ \\
\hline Median (IQR) & $95.59(88.24 ; 100.0)$ \\
\hline \multicolumn{2}{|l|}{ KOOS sport, \% } \\
\hline Mean $\pm S D$ & $70.87 \pm 26.37$ \\
\hline Median (IQR) & $75.0(55.0 ; 90.0)$ \\
\hline \multicolumn{2}{|l|}{ KOOS QoL, \% } \\
\hline Mean $\pm S D$ & $53.83 \pm 22.86$ \\
\hline Median (IQR) & $50.0(37.50 ; 75.0)$ \\
\hline \multicolumn{2}{|l|}{ Total KOOS, \% } \\
\hline Mean \pm SD & $77.58 \pm 14.98$ \\
\hline Median (IQR) & $79.61(70.60 ; 89.29)$ \\
\hline
\end{tabular}

ACLR, anterior cruciate ligament reconstruction; TAS-Ar, Arabic version of the Tegner activity scale; IKDC, International Knee Documentary Committee; KOOS, Knee Injury and Osteoarthritis Outcome Score; ADL, activities of daily living; QoL, quality of life; SD, standard deviation; IQR, inter-quartile range. *Values are mean \pm standard deviation, unless otherwise indicated

\subsection{Floor and Ceiling Effects}

Floor and ceiling effects of TAS-Ar were evaluated using data from 75 patients with ACLR. For the floor effect, none of the patients scored the lowest possible score (Tegner $=0$ ) on the TAS-Ar. For the ceiling effect, only two patients (2.7\%) scored the highest possible score $($ Tegner $=10)$ on the TAS-Ar.

\subsection{Test-Retest Reliability}

The reliability of the TAS-Ar was excellent, with an ICC of 0.836 (95\% CI, 0.687-0.914; $p<0.001$ ). The SEM was 0.862 , the $\mathrm{SDC}_{\text {individual }}$ was 2.39 , and the $\mathrm{SDC}_{\text {group }}$ was 0.41 . The reliability assessment was conducted using data from 39 patients who completed the TAS-Ar twice, with a mean of $8.92 \pm 5.57$ days between tests. The mean TAS-Ar score was $4.10 \pm 2.16$ at the first test and $4.23 \pm 2.09$ at the second test (Table 3). No significant difference was found in the TAS-Ar score between the two testing sessions $(p=0.622)$.

Table 3. The test-retest reliability of the Arabic version of the Tegner activity scale (Patients $n=39$ ).

\begin{tabular}{ll}
\hline & Tegner Activity Scale-Arabic \\
\hline 1st test & \\
Mean \pm SD & $4.10 \pm 2.16$ \\
Median (IQR) & $4(2 ; 6)$ \\
\hline 2nd test & $4.23 \pm 2.09$ \\
Mean \pm SD & $4(3 ; 6)$ \\
Median (IQR) & 0.13 \\
\hline Mean difference & $0.836(0.687-0.914)$ \\
\hline ICC (95\% CI) & 0.862 \\
\hline SEM & 2.39 \\
\hline SDC
\end{tabular}


Table 3. Cont.

\begin{tabular}{ll}
\hline & Tegner Activity Scale-Arabic \\
\hline SDC group & 0.41 \\
\hline $\begin{array}{l}\text { ICC, intraclass correlation coefficient; CI, confidence interval; SEM, standard error of measurement; SDC, smallest } \\
\text { detectable change; SD, standard deviation; IQR, inter-quartile range. }\end{array}$
\end{tabular}

\subsection{Construct Validity}

The results showed that the TAS-Ar was significantly correlated with the IKDC (Spearman's rho $=0.476, p<0.001$ ), all KOOS subscales (Spearman's rho $=0.195-0.497, p<0.05$ ), and the KOOS total score (Spearman's rho $=0.469, p<0.001$ ). A summary of the correlation results is presented in Table 4 .

Table 4. Correlations between the Arabic version of the Tegner activity scale and other outcome measures in patients with $\operatorname{ACLR}(n=75)$.

\begin{tabular}{lll}
\hline & \multicolumn{2}{c}{ Tegner Activity Scale-Arabic } \\
\cline { 2 - 3 } & Spearman's Rho & $\boldsymbol{p}$ \\
\hline IKDC & 0.476 & $<0.001$ \\
KOOS symptoms & 0.272 & 0.009 \\
KOOS pain & 0.195 & 0.047 \\
KOOS ADL & 0.358 & $<0.001$ \\
KOOS sport & 0.458 & $<0.001$ \\
KOOS QoL & 0.497 & $<0.001$ \\
KOOS total & 0.469 & $<0.001$ \\
\hline
\end{tabular}

IKDC, International Knee Documentary Committee; KOOS, Knee Injury and Osteoarthritis Outcome Score; ADL, activities of daily living; QoL, quality of life.

\section{Discussion}

The goal of this study was to translate, cross-culturally adapt, and validate the Arabic version of the TAS in patients with ACLR. The test-retest reliability of the TAS-Ar was excellent, and the construct validity of the scale showed a moderate correlation with the IKDC and KOOS scales. These findings suggest that the TAS-Ar has acceptable psychometric properties, which are comparable to those of the original English version of the scale [4], as well as to adaptation studies of the scale to other languages [10,11].

Our results showed that TAS-Ar has excellent test-retest reliability. The reliability of the scale was 0.836, which is comparable to the reliability of the original English version of the scale (ICC $=0.82$ ) in patients with ACLR [4]. The reliability of the TAS-Ar is also similar to that of the previous adaptation of the scale into Dutch (ICC $=0.97)$ [11] and SimplifiedChinese (ICC $=0.99)$ [10] in patients post-ACLR. Furthermore, our results are comparable to the results of the Persian version in patients with ACL injury (ICC $=0.81$ ) [12] and the Greek version in patients with ACL and other knee injuries (ICC $=0.87$ ) [13]. In our study, patients who completed the TAS-Ar for test-retest reliability reported no changes in knee function, no recurrent knee injury, and no other injury in any part of the body between the two testing sessions. We also found no significant differences in the TAS-Ar between the two testing sessions $(p=0.622)$.

The construct validity was determined by comparing the TAS-Ar with the Arabic versions of the IKDC and KOOS scales. The results showed that the TAS-Ar was positively and moderately correlated with the IKDC (Spearman's rho $=0.477)$. Similarly, the original English version of the TAS was positively and significantly correlated with the IKDC (Spearman's rho $=0.22, p=0.001$ ) [4]. Moreover, previous adaptation studies of the TAS found that the scale was positively and significantly correlated with the IKDC, with correlation coefficients ranging from 0.42 to $0.66[10,11]$. Together, these findings indicate that higher level work/sports activities are related to better knee function.

With regard to the correlation between the TAS-Ar and KOOS subscales, we found that the TAS-Ar had higher correlations with the KOOS subscales that measure activities of daily 
living, sports, and knee-related QoL. In contrast, the TAS-Ar showed poor to no correlation with the KOOS subscales that measure symptoms and pain, respectively. These results indicate that patients with higher levels of work/sports activities are likely to have better activities of daily living, higher sports performance, and better knee-related QoL, while having lower knee symptoms and pain. In agreement with these findings, Brigg et al. [4] found that patients with less difficulty in activities of daily living and sports had higher Tegner activity levels than those with more difficulty.

Another interesting finding of this study was the positive and moderate correlation between the TAS-Ar and knee-related QoL subscale of KOOS. This finding suggests that higher levels of work/sport activities are associated with better knee-related QoL, as mentioned earlier. In contrast to our findings, the Persian version of the TAS did not correlate with the KOOS-QoL subscale [12]. This could be due to the fact that the Persian study was conducted on patients with ACL injury, whereas our study was performed on patients following ACLR. Nonetheless, in support of our findings in patients with ACLR, a previous study found that patients who did not return to their pre-injury level of activity had a worse knee-related QoL than those who returned to their pre-injury level of activity [20].

This study had some limitations. First, the participants were all men; therefore, the findings cannot be generalized to women. Another limitation was that the responsiveness of the TAS-Ar was not measured. Future studies should investigate the responsiveness of the TAS-Ar to detect clinically relevant changes in activity levels over time during rehabilitation following ACLR. Furthermore, more studies are needed to assess the psychometric properties of the TAS-Ar in other patient populations with different knee-related impairments, such as ACL injury (before surgery), meniscal injury, or patellar dislocation.

\section{Conclusions}

Our study showed that the Arabic version of the TAS is a reliable and valid self-report questionnaire that can be used to evaluate the level of activity/sport in Arabic-speaking patients following ACLR.

Author Contributions: Conceptualization, M.A., H.A. and Y.S.A.; methodology, M.A., H.A. and Y.S.A.; validation, M.A., H.A. and Y.S.A.; formal analysis, Y.S.A.; investigation, M.A., H.A. and Y.S.A.; resources, M.A., H.A. and Y.S.A.; data curation, M.A., H.A. and Y.S.A.; writing-original draft preparation, M.A., H.A. and Y.S.A.; writing—review and editing, M.A., H.A. and Y.S.A.; visualization, M.A., H.A. and Y.S.A.; supervision, M.A., H.A. and Y.S.A.; project administration, M.A., H.A. and Y.S.A.; funding acquisition, M.A., H.A. and Y.S.A. All authors have read and agreed to the published version of the manuscript.

Funding: This study was funded by the deputyship for Research \& Innovation, Ministry of Education in Saudi Arabia under Project Number IFP-2020-22.

Institutional Review Board Statement: This study was approved by the Research Ethics Committee of Majmaah University (Ethics number: MUREC-Dec.3/COM-2019/12-2).

Informed Consent Statement: Informed consent was obtained from all subjects involved in the study.

Data Availability Statement: On request to the corresponding author.

Acknowledgments: The authors extend their appreciation to the deputyship for Research \& Innovation, Ministry of Education in Saudi Arabia for funding this research work through the project number (IFP-2020-22).

Conflicts of Interest: The authors declare no conflict of interest.

\section{References}

1. Tayeb, A.M.; Almohammadi, A.A.; Hegaze, A.H.; Roublah, F.; Althakafi, K.A. Anterior Cruciate Ligament Injury in Association with Other Knee Injuries in King Abdulaziz University Hospital, Saudi Arabia. Cureus 2020, 12, e10240. [CrossRef] [PubMed]

2. Kiapour, A.M.; Murray, M.M. Basic science of anterior cruciate ligament injury and repair. Bone Jt. Res. 2014, 3, 20-31. [CrossRef] [PubMed] 
3. Myklebust, G.; Bahr, R. Return to play guidelines after anterior cruciate ligament surgery. Br. J. Sports Med. 2005, 39, 127-131. [CrossRef] [PubMed]

4. $\quad$ Briggs, K.K.; Lysholm, J.; Tegner, Y.; Rodkey, W.G.; Kocher, M.S.; Steadman, J.R. The reliability, validity, and responsiveness of the Lysholm score and Tegner activity scale for anterior cruciate ligament injuries of the knee: 25 years later. Am. J. Sports Med. 2009, 37, 890-897. [CrossRef] [PubMed]

5. Tegner, Y.; Lysholm, J. Rating systems in the evaluation of knee ligament injuries. Clin. Orthop. Relat. Res. 1985, 198, 43-49. [CrossRef]

6. Collins, N.J.; Misra, D.; Felson, D.T.; Crossley, K.M.; Roos, E.M. Measures of knee function: International Knee Documentation Committee (IKDC) Subjective Knee Evaluation Form, Knee Injury and Osteoarthritis Outcome Score (KOOS), Knee Injury and Osteoarthritis Outcome Score Physical Function Short Form (KOOS-PS), Knee Outcome Survey Activities of Daily Living Scale (KOS-ADL), Lysholm Knee Scoring Scale, Oxford Knee Score (OKS), Western Ontario and McMaster Universities Osteoarthritis Index (WOMAC), Activity Rating Scale (ARS), and Tegner Activity Score (TAS). Arthritis Care Res. 2011, 63 (Suppl. 11), S208-S228.

7. Hamrin Senorski, E.; Svantesson, E.; Beischer, S.; Thomee, C.; Thomee, R.; Karlsson, J.; Samuelsson, K. Low 1-Year Return-to-Sport Rate After Anterior Cruciate Ligament Reconstruction Regardless of Patient and Surgical Factors: A Prospective Cohort Study of 272 Patients. Am. J. Sports Med. 2018, 46, 1551-1558. [CrossRef] [PubMed]

8. Letchford, R.; Button, K.; Sparkes, V.; van Deursen, R.W.M. Assessing activity participation in the ACL injured population: A systematic review of activity rating scale measurement properties. Phys. Ther. Rev. 2013, 17, 99-109. [CrossRef]

9. Toole, A.R.; Ithurburn, M.P.; Rauh, M.J.; Hewett, T.E.; Paterno, M.V.; Schmitt, L.C. Young Athletes Cleared for Sports Participation After Anterior Cruciate Ligament Reconstruction: How Many Actually Meet Recommended Return-to-Sport Criterion Cutoffs? J. Orthop. Sports Phys. Ther. 2017, 47, 825-833. [CrossRef] [PubMed]

10. Huang, H.; Zhang, D.; Jiang, Y.; Yang, J.; Feng, T.; Gong, X.; Wang, J.; Ao, Y. Translation, Validation and Cross-Cultural Adaptation of a Simplified-Chinese Version of the Tegner Activity Score in Chinese Patients with Anterior Cruciate Ligament Injury. PLoS ONE 2016, 11, e0155463. [CrossRef] [PubMed]

11. Eshuis, R.; Lentjes, G.W.; Tegner, Y.; Wolterbeek, N.; Veen, M.R. Dutch Translation and Cross-cultural Adaptation of the Lysholm Score and Tegner Activity Scale for Patients with Anterior Cruciate Ligament Injuries. J. Orthop. Sports Phys. Ther. 2016, 46, 976-983. [CrossRef] [PubMed]

12. Negahban, H.; Mostafaee, N.; Sohani, S.M.; Mazaheri, M.; Goharpey, S.; Salavati, M.; Zahednejad, S.; Meshkati, Z.; Montazeri, A. Reliability and validity of the Tegner and Marx activity rating scales in Iranian patients with anterior cruciate ligament injury. Disabil. Rehabil. 2011, 33, 2305-2310. [CrossRef] [PubMed]

13. Panagopoulos, A.; Billis, E.; Floros, G.R.; Stavropoulos, T.; Kaparounaki, E.; Moucho, M.; Paskou, A.; Tegner, Y. Cross-Cultural Adaptation of the Greek Versions of the Lysholm Knee Scoring Scale and Tegner Activity Scale. Cureus 2020, 12, e9372. [CrossRef] [PubMed]

14. Wirth, B.; Meier, N.; Koch, P.P.; Swanenburg, J. Development and evaluation of a German version of the Tegner activity scale for measuring outcome after anterior cruciate ligament injury. Sportverletz. Sportschaden 2013, 27, 21-27. [PubMed]

15. Beaton, D.E.; Bombardier, C.; Guillemin, F.; Ferraz, M.B. Guidelines for the process of cross-cultural adaptation of self-report measures. Spine 2000, 25, 3186-3191. [CrossRef] [PubMed]

16. Alfadhel, S.A.; Vennu, V.; Alnahdi, A.H.; Omar, M.T.; Alasmari, S.H.; AlJafri, Z.; Bindawas, S.M. Cross-cultural adaptation and validation of the Saudi Arabic version of the Knee Injury and Osteoarthritis Outcome Score (KOOS). Rheumatol. Int. 2018, 38, 1547-1555. [CrossRef] [PubMed]

17. Almalki, H.; Herrington, L.; Jones, R. Cross-cultural adaptation, Reliability, Internal Consistency and validation of the Arabic version of the International Knee Documentation Committee subjective knee form (IKDC) for Arabic people with ACLR. In Proceedings of the 5th International Conference on Physiotherapy, Dubai, United Arab Emirates, 27-29 November 2017; Volume 7, p. 90.

18. Terwee, C.B.; Bot, S.D.; de Boer, M.R.; van der Windt, D.A.; Knol, D.L.; Dekker, J.; Bouter, L.M.; de Vet, H.C. Quality criteria were proposed for measurement properties of health status questionnaires. J. Clin. Epidemiol. 2007, 60, 34-42. [CrossRef] [PubMed]

19. Cohen, J. A power primer. Psychol Bull. 1992, 112, 155-159. [CrossRef] [PubMed]

20. Kvist, J.; Ek, A.; Sporrstedt, K.; Good, L. Fear of re-injury: A hindrance for returning to sports after anterior cruciate ligament reconstruction. Knee Surg. Sports Traumatol. Arthrosc. 2005, 13, 393-397. [CrossRef] [PubMed] 